\title{
A ANTA DOS CURRAIS DO GALHORDAS (CASTELO DE VIDE - CENTRO LESTE DE PORTUGAL): RESULTADOS DA PRIMEIRA CAMPANHA DE ESCAVAÇÃO
}

\author{
SÉRGIO MONTEIRO-RODRIGUES ${ }^{(1)}$
}

Resumo:

\begin{abstract}
A Anta dos Currais do Galhordas é um monumento megalítico composto por câmara poligonal, corredor e mamoa. A primeira campanha de escavação permitiu a identificação de algumas técnicas usadas na sua construção, bem como a recolha de diversos artefactos, nomeadamente material em pedra lascada (raro) e em pedra polida, placas de xisto (uma lisa e uma gravada) e vasos cerâmicos. No âmbito do estudo destes últimos procedeu-se à análise do conteúdo de um recipiente através de cromatografia gasosa com detecção por massa.

Não se dispõe ainda de datações absolutas para a anta. Todavia, a tipologia dos recipientes cerâmicos aponta para uma cronologia que deverá andar próxima da transição do IV para o III milénio cal BC.

Com os trabalhos realizados neste monumento - inscritos num plano de valorização patrimonial promovido pela Câmara Municipal de Castelo de Vide - pretende-se contribuir para um melhor conhecimento do fenómeno tumular megalítico, não só do Alto Alentejo, como da Península Ibérica em geral.
\end{abstract}

Palavras-chave: Anta dos Currais do Galhordas, Megalitismo, Alto Alentejo

\begin{abstract}
:
The megalithic tomb of Currais do Galhordas: (Castelo de Vide - Central Eastern Portugal): Results of the first season of excavation.

Anta dos Currais do Galhordas is a megalithic passage tomb complete with mound and a chamber of polygonal plan. The first season of excavation has identified several of the building techniques that were employed in its construction; and recovered associated artefacts such as flaked (rare) and polished stone-tools, engraved and non-engraved slate plaques, and pottery. One vessel has been sent for content analysis by gas chromatography coupled to mass spectrometry.

Absolute dating is not available yet. However, the pottery typology suggests that the monument was built between the end of the 4th millennium cal BC and the beginning of the 3rd millennium cal BC.

The research that is being carried out at Anta dos Currais do Galhordas - financed by the Municipality of Castelo de Vide within a project of heritage promotion - aims to contribute to a better understanding of the megalithic phenomenon, not only in the Alentejo region, but also in the Iberian Peninsula in general.
\end{abstract}

Keywords: Anta dos Currais do Galhordas, Megalithism, Alto Alentejo

Received: 2 October, 2013; Accepted: 7 November, 2013

\section{INTRODUÇÃO}

O concelho de Castelo de Vide é bastante rico em sepulturas megalíticas, encontrando-se inventariadas até ao momento mais de trinta. Estes monumentos evidenciam alguma diversidade arquitectónica e normalmente fornecem material arqueológico em abundância e em óptimo estado de conservação. Por este facto encerram um enorme potencial no que diz respeito ao conhecimento do fenómeno tumular megalítico, não só do Alentejo (p.e. ANDRADE 2009; BUENO RAMÍREZ et al. 2006, 2008a, 2010, 2012; OLIVEIRA 1997, 2000; OLIVEIRA et al. 2007; PARreira 1996), como da Península Ibérica em geral.

Para além da vertente científica, esta realidade arqueológica tem sido também perspectivada como

\section{A memória de José Bica}

mais-valia em termos de promoção e desenvolvimento regional. Efectivamente, a escavação da Anta dos Currais do Galhordas surge no contexto de um projecto de valorização turística, cultural e ambiental da área envolvente da albufeira da barragem de Póvoa e Meadas, promovido pela Câmara Municipal de Castelo de Vide $(\mathrm{CMCV})$. Este projecto insere-se numa estratégia ainda mais alargada da Autarquia, que contempla a conservação e a musealização de sítios arqueológicos, bem como a sua integração em redes que articulem património científico, natural e cultural. Assim, prevê-se que as intervenções arqueológicas possam vir a estender-se a outros monumentos da região, não só pela necessidade de responder a problemas decorrentes da investigação, mas também como forma de divulgar o Passado junto do público em geral.

(1) Universidade do Porto. Faculdade de Letras. Departamento de Ciências e Técnicas do Património, Via Panorâmica, s/n. 4150-564 Porto. Portugal Investigador do Centro de Estudos Arqueológicos das Universidades de Coimbra e Porto. 
Ainda no quadro desta valorização patrimonial, foi proposta a classificação da Anta dos Currais do Galhordas como Imóvel de Interesse Municipal.

\section{ENQUADRAMENTO FISIOGRÁFICO}

A Anta dos Currais do Galhordas localiza-se junto à albufeira da barragem de Póvoa e Meadas, no lugar de Tapada do Souto. Pertence à freguesia de $\mathrm{S}$. João Baptista, concelho de Castelo de Vide, distrito de Portalegre. As suas coordenadas geográficas são as seguintes: $39^{\circ} 27^{\prime} 40,4^{\prime \prime} \mathrm{N} 07^{\circ} 32^{\prime} 39,9^{\prime \prime} \mathrm{W}$. A respectiva cota ronda os 330 m a.n.m.
Do ponto de vista geológico, o monumento megalítico encontra-se numa região dominada pelo granito (granito calco-alcalino, porfiróide, de grão grosseiro, segundo FERNANDES et al. 1972), rocha que foi usada na sua construção.

A Anta dos Currais do Galhordas foi erigida num vale pouco profundo onde corre, aproximadamente de sul para norte, uma linha de água sazonal, afluente da Ribeira de Nisa. Este vale encontra-se delimitado, a este e a oeste, por relevos graníticos de baixa altitude. Tais relevos evidenciam uma densa rede de diaclases, que poderá ter facilitado a extracção das lajes usadas na construção do monumento megalítico (Fig. 1).

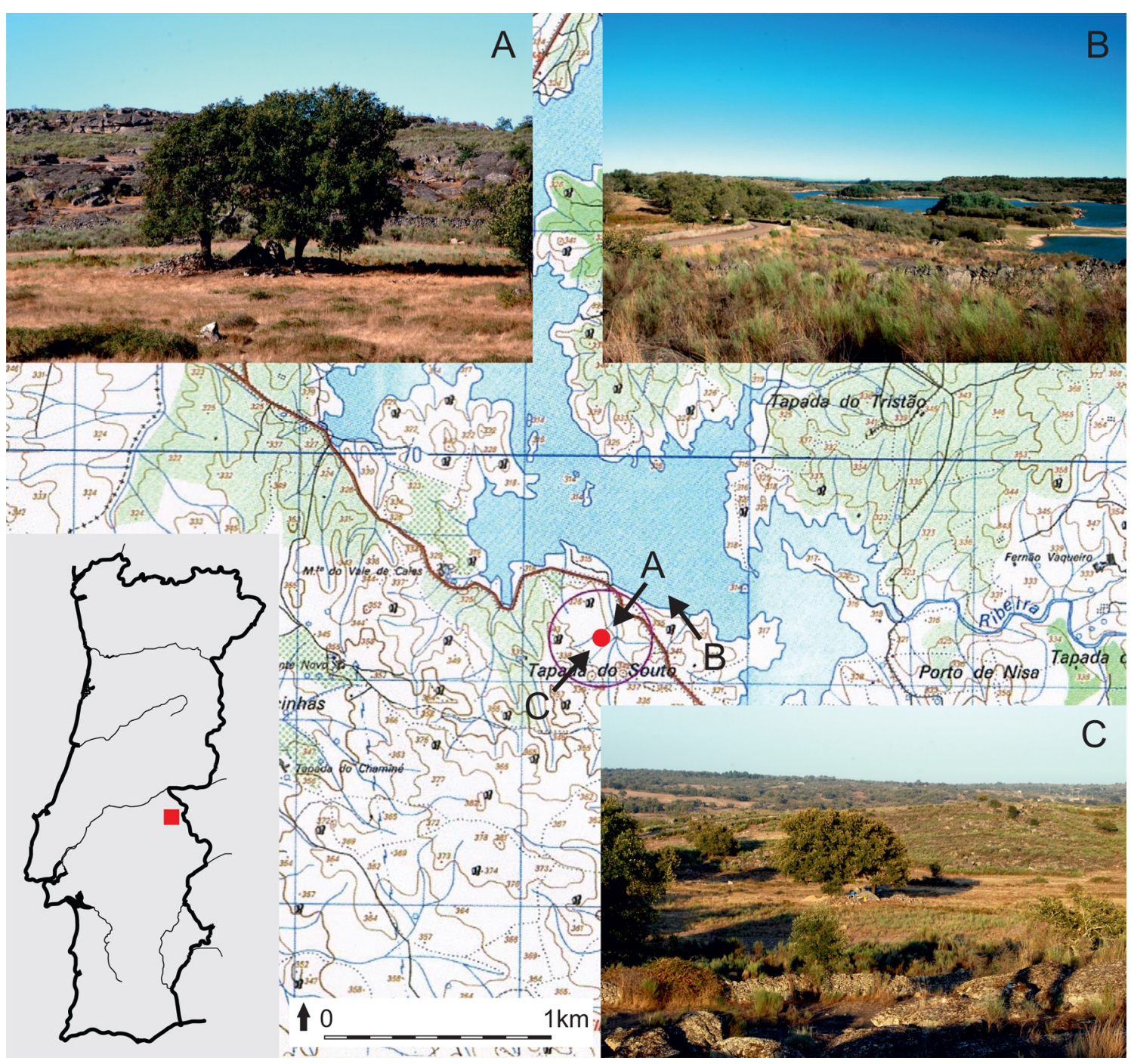

Fig. 1. Localização da Anta dos Currais do Galhordas (cartografia: Carta Militar de Portugal, na escala 1:25000, folha 335 (Castelo de Vide), 1999). A - A Anta vista de nordeste. B - Vista para noroeste da albufeira da barragem de Póvoa e Meadas. Em relação à foto, a Anta localiza-se a cerca de $200 \mathrm{~m}$ para a esquerda. C - Implantação da Anta: Em primeiro plano são visíveis os afloramentos graníticos que constituem o relevo que delimita o vale do lado sudoeste; em segundo plano está a Anta (entre as árvores); em terceiro plano é visível um alinhamento de arbustos que traça o leito da linha de água; para lá do alinhamento surge o outro relevo granítico que delimita o vale do lado nordeste. Por detrás desse relevo encontra-se a Ribeira de Nisa (actualmente, a albufeira da barragem de Póvoa e Meadas).

Fig. 1. Location of Anta dos Currais do Galhordas (cartography: Carta Militar de Portugal, na escala 1:25000, folha 335 (Castelo de Vide), 1999). A - View from NE. B - Póvoa e Meadas dam lake. View towards NW. C - View from SW (the Anta is in the center of the photo among the trees). 


\section{A DESCOBERTA DA ANTA}

A Anta dos Currais do Galhordas foi inventariada pela Secção de Arqueologia da CMCV apenas em 1993, na sequência de informações orais que revelaram a sua existência. Esta inventariação tardia no contexto da inventariação dos monumentos megalíticos do concelho decorreu do facto do monumento se encontrar, à época, totalmente soterrado por um enorme amontoado de pedras, acumulado ao longo de séculos de trabalhos agrícolas. A maior parte destas pedras deverá estar relacionada com o monumento, mais precisamente com a respectiva mamoa. Aparentemente, os trabalhos agrícolas terão sido responsáveis pelo arrasamento do tumulus e pela posterior acumulação das pedras em torno da anta, até ao seu soterramento total.

Embora tenham dificultado a sua identificação, as pedras acumuladas contribuíram, em parte, para a conservação do depósito que contém o material arqueológico, sobretudo nas áreas da câmara e do corredor.

$\mathrm{Na}$ altura da inventariação (1993), a equipa da Secção de Arqueologia procedeu ao corte e à queima de mato, e à remoção da maior parte das pedras para a periferia do monumento megalítico. Durante estas acções encontraram-se à superfície alguns materiais pré-históricos, e foram postos a descoberto as lajes da câmara funerária, esteios do corredor (sem que, contudo, a sua morfologia e orientação tivessem ficado perfeitamente definidas) e a laje de cobertura, que se encontrava tombada.

Foi igualmente realizado um levantamento topográfico preliminar da área em torno da anta, bem como uma primeira versão da respectiva planta (vide Processo Anta dos Currais do Galhordas, Secção de Arqueologia da Câmara Municipal de Castelo de Vide, inventário n ${ }^{\circ} 164-$ documento interno da Secção de Arqueologia da CMCV).

Parte destes e de outros trabalhos viriam, posteriormente, a ser coligidos por Jorge de Oliveira na sua dissertação de doutoramento, a qual surge como importante síntese sobre o megalitismo alto-alentejano (OLIVEIRA 1997).

\section{A PRIMEIRA CAMPANHA DE ESCAVAÇÃO: OBJECTIVOS E METODOLOGIA}

A primeira campanha de escavação na Anta dos Currais do Galhordas realizou-se em Setembro de 2011, estando a sua coordenação a cargo do signatário. Nela participaram alunos do Mestrado em Arqueologia da Faculdade de Letras da Universidade do Porto e membros da Secção de Arqueologia da CMCV.

No seguimento de uma apreciação preliminar feita ao monumento megalítico durante o mês de
Março daquele mesmo ano, estabeleceram-se como principais objectivos de trabalho:

- a determinação da morfologia da câmara funerária;

- a determinação da posição e morfologia do corredor;

- a delimitação da extensão da mamoa, pelo menos num dos quadrantes do monumento;

- a caracterização de aspectos de natureza arquitectónica;

- $\quad$ a caracterização do respectivo espólio;

- a avaliação do estado global de conservação da anta.

Em função destes objectivos, a intervenção incidiu na área assinalada na figura 2, no sentido de se esclarecerem, de forma mais específica, os seguintes aspectos:

a) Quadrículas B-C-D/1 e B-C-D/2:

- Observar o contacto entre a mamoa e a câmara funerária, e caracterizar eventual estrutura de contrafortagem;

- Observar a estruturação interna da mamoa (sobretudo nas quadrículas C-D/1 e C-D/2);

b) Quadrículas B-C-D-E-F-G-H/1:

- Avaliar a extensão da mamoa e verificar a eventual existência de anel lítico periférico ou de outra estrutura delimitadora do tumulus;

c) Quadrículas A-B/1, A-B/2 e A/3:

- Caracterizar a área da câmara megalítica, identificar os vestígios ligados às deposições funerárias e procurar estabelecer correlações estratigráficas entre si;

- Caracterizar o "espaço" de ligação entre a câmara funerária e o corredor do monumento;

d) Quadrículas A/3-4-5 e Z/5

- Definir a orientação e a morfologia do corredor;

- Identificar eventuais vestígios relacionados com a sua utilização;

- Detectar o esteio do corredor da quadrícula Z'/5 (não visível no início dos trabalhos);

e) Quadrículas B/3-4-5-6

- Observar o contacto entre a mamoa e a câmara funerária;

- Observar o contacto entre a mamoa e o corredor intratumular.

No que diz respeito à metodologia de escavação, seguiu-se a normalmente usada no estudo de monumentos megalíticos (p.e. CRUZ 2001; JORGE 1990; JORGE \& BETTENCOURT 1988; OLIVEIRA 1997). Assim, procedeu-se à decapagem horizontal nas áreas preenchidas por sedimentos finos (essencialmente na câmara e no corredor). Nas áreas com componente pétrea (fundamentalmente na mamoa), desmontaram-se as camadas de pedras procurando respeitar os planos segundo os quais elas foram sobrepostas. Estes 
planos foram, na sua totalidade, fotografados e desenhados na escala $1 / 20$.

No depósito arqueológico preservado da câmara e do corredor conservou-se uma banqueta com cerca de $40 \mathrm{~cm}$ de largura, entre a quadrícula A1 e a A5 (Fig. 2), com o objectivo de se criar um perfil que permitisse a análise da estratigrafia destes dois espaços. Todavia, a textura homogénea dos sedimentos, a ausência de variações de cor e, sobretudo, a inexistência de camadas definidas por limites superiores e inferiores nítidos tornou este procedimento infrutífero.
No sentido de evitar a perda de eventuais fragmentos de osso, de elementos carpológicos ou antracológicos e de materiais arqueológicos de reduzidas dimensões (contas de colar, por exemplo) optou-se pela crivagem integral dos sedimentos retirados do monumento.

Uma vez que se pretendia analisar o conteúdo dos vasos cerâmicos detectados, estes foram imediatamente selados após a exumação, conservando-se intacto quer o material que os enchia, quer o sedimento que os envolvia.

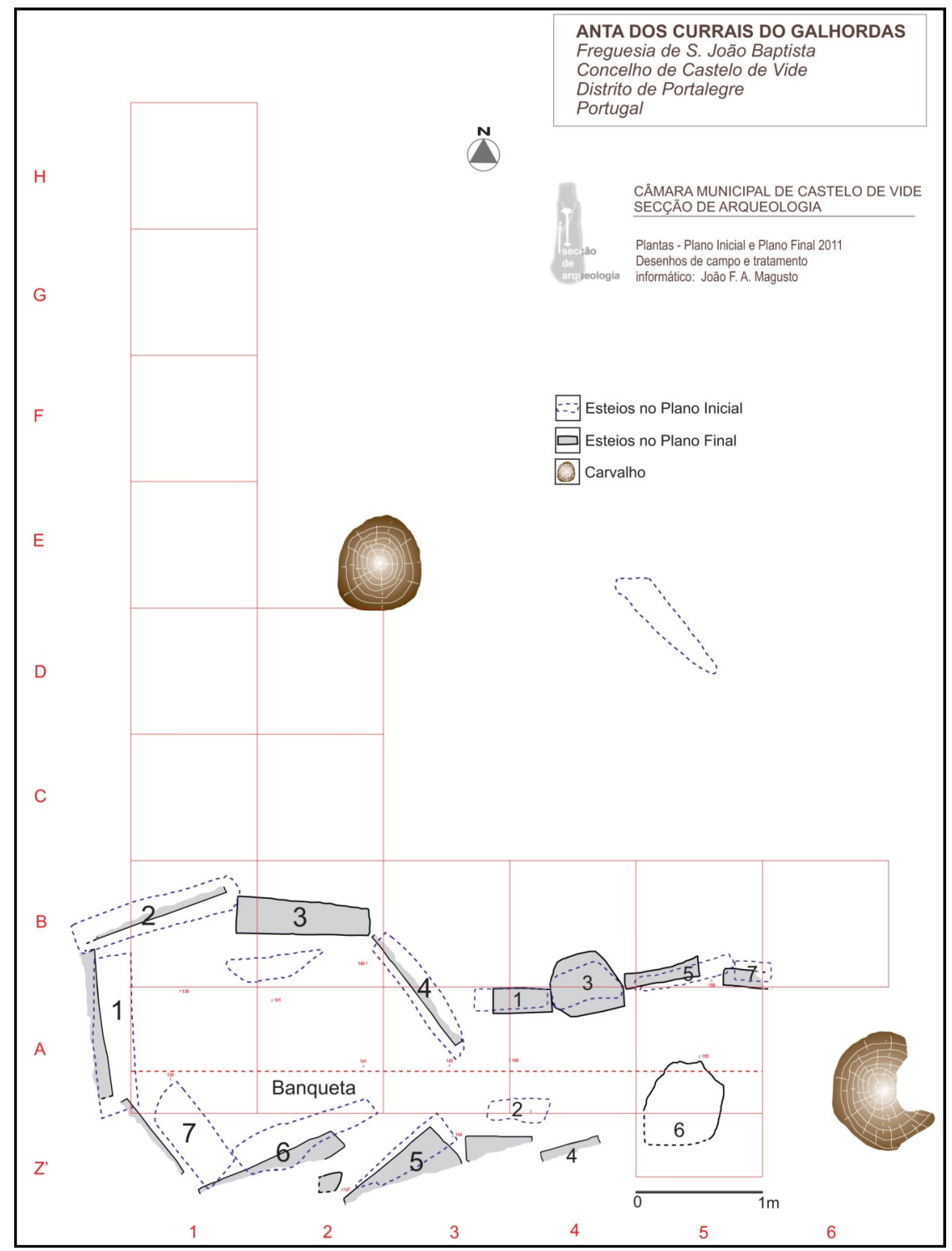

Fig. 2. Planta da Anta dos Currais do Galhordas. Área intervencionada (quadrículas de 1m2). Representação dos esteios no início e no fim da escavação (o esteio 1 da câmara corresponde ao esteio de cabeceira).

Fig. 2. Plan of Anta dos Currais do Galhordas located in relation to the excavation grid. Orthostat 1 is a chamber backstone. 


\section{PRIMEIROS RESULTADOS}

Alguns resultados desta primeira campanha de escavação foram já divulgados pelo autor deste texto no encontro internacional II Mesa-Redonda Artes Rupestres da Pré-história e da Proto-história 2011, realizado na Faculdade de Letras da Universidade do Porto. Neste texto acrescentam-se novos dados, também eles preliminares, resultantes da prossecução da investigação.

\subsection{A Câmara Funerária}

A Anta dos Currais do Galhordas - uma anta com corredor longo descentrado em relação ao eixo de simetria do monumento (ANDRADE 2009; LEISNER \& LEISNER 1951; OLIVEIRA 1997) apresenta câmara poligonal definida por sete esteios (número de esteios recorrente na região, segundo OLIVEIRA 1997), atingindo o mais alto cerca de $2,80 \mathrm{~m}$. Dois destes esteios estão fracturados sensivelmente a um terço da altura total (Fig. 3).

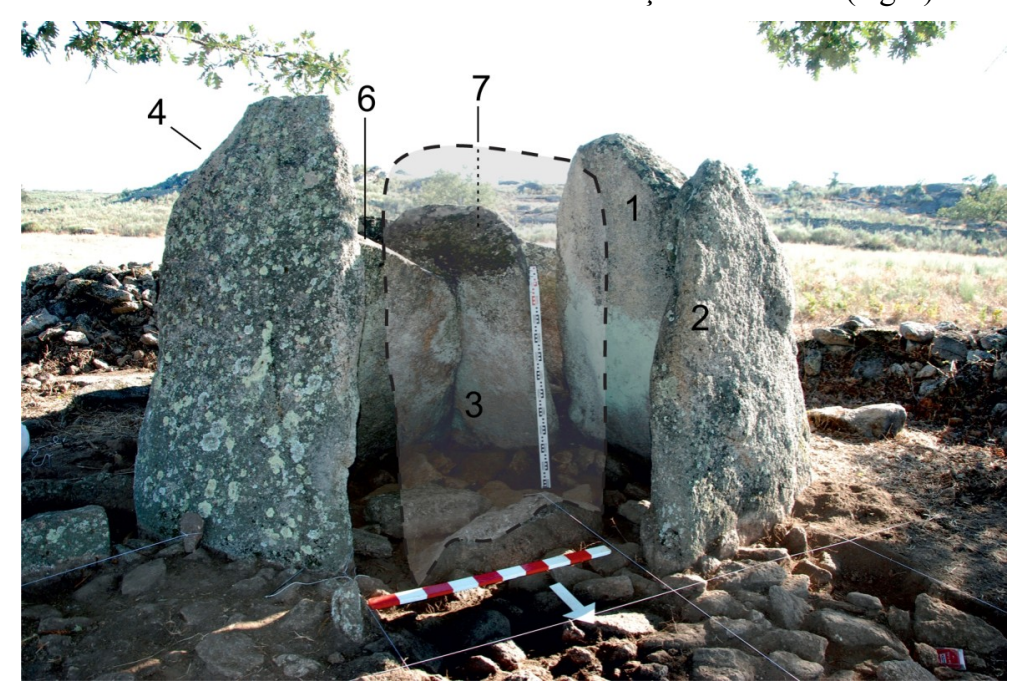

Fig. 3. Câmara funerária poligonal vista de NE. Observe-se em primeiro plano um dos esteios fracturados, reconstituído graficamente. $\mathrm{O}$ esteio de cabeceira é o segundo à direita do fracturado. À esquerda é visível um esteio do corredor. O interior da câmara encontrava-se colmatado com diversas "camadas" de pedras que selaram o nível arqueológico conservado.

Fig. 3. The polygonal chamber viewed from the northeast. One of the fractured orthostats has been digitally reconstructed. An orthostat from the passage can be observed on the left side of the image. The chamber was sealed with stone fill sealing the archaeological layer.

A laje de cobertura da câmara funerária encontra-se tombada e encostada à anta, no lado sul. Aparentemente, a pressão exercida por esta laje provocou a inclinação de alguns dos esteios no sentido do interior da câmara (Fig. 4).

Aquando dos inícios da escavação verificouse que a câmara funerária continha espessas "camadas" de blocos de granito a colmatá-la (Fig. 3). Tais blocos, relacionados com os trabalhos agrícolas acima referidos, encontram-se representados nas plantas 1, 2, 3 e 4 (Fig. 5).

$\mathrm{O}$ nível arqueológico conservado surgiu somente sob os blocos da planta 4, a partir da cota $-117 \mathrm{~cm}$ (Fig. 6, planta 5). Acima desta cota, e em associação ao referido enchimento pétreo da câmara funerária, recolheram-se essencialmente materiais pós pré-históricos, nomeadamente cerâmicas, objectos metálicos e uma moeda (ainda não classificada).

A câmara funerária foi escavada até ao bedrock. Como se referiu, não foi possível reconhecer no depósito que a enchia qualquer estratificação.

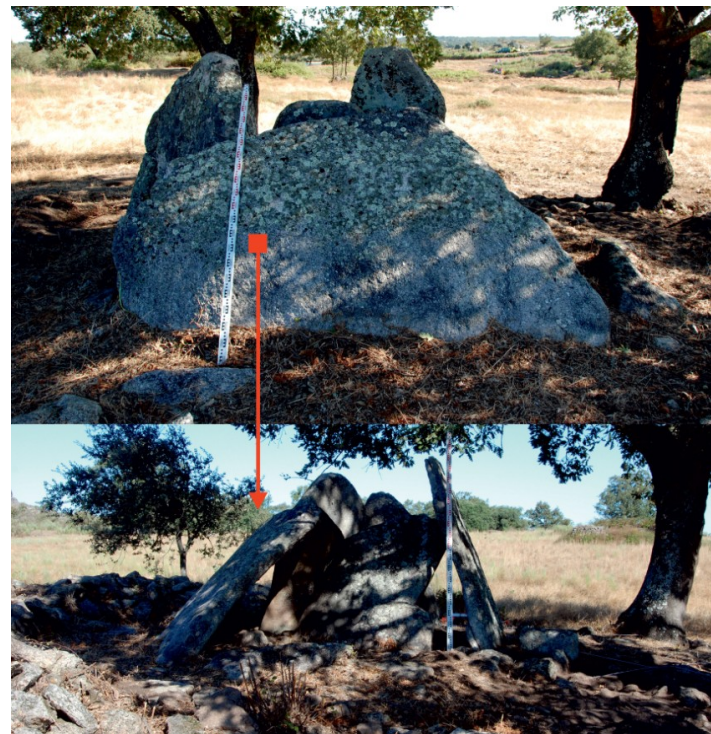

Fig. 4. A laje de cobertura da câmara funerária encostada ao monumento. Vista para nordeste.

Fig. 4. The fallen capstone is now placed against the chamber walls. Northeast view. 


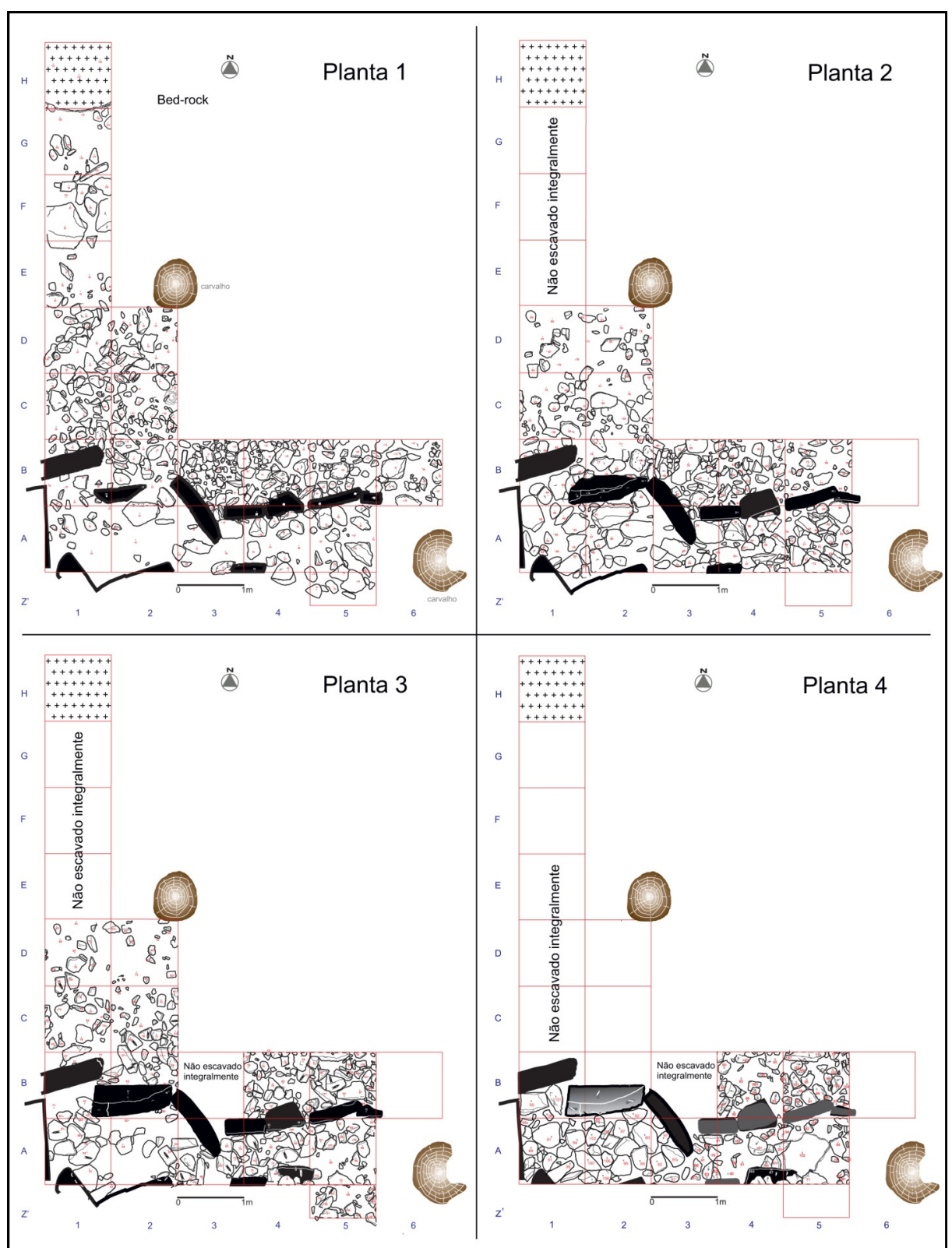

Fig. 5. Plantas da área escavada (planos 1, 2, 3 e 4). No exterior do monumento estão representadas as diferentes camadas de pedras da mamoa. No interior da câmara e no corredor podem ver-se as pedras que os colmatavam.

Fig. 5. Plans of the excavated area (plans 1, 2, 3 and 4). Several layers of cairn material represented in the area adjacent to the chamber. Blocking stones are also evidenced inside the chamber and the passage.

\subsection{O Corredor}

Apesar de se perceber que a Anta dos Currais do Galhordas possuía corredor globalmente voltado a este (OLIVEIRA 1997), no início dos trabalhos a sua posição exacta e a sua morfologia não eram claras. À semelhança da câmara funerária, também o corredor se encontrava colmatado por blocos de granito, que cobriam parcialmente o topo dos respectivos esteios. Por outro lado, a presença de um carvalho de grande porte no seu alinhamento não permitia avaliar o seu comprimento total (foi possível escavá-lo apenas numa extensão de cerca de $3 \mathrm{~m}$ ), nem aferir a correcta orientação (Figs. 5e 7).

Os materiais arqueológicos associados às camadas pétreas que enchiam o corredor são, tal como na câmara funerária, fundamentalmente de idade moderna/ contemporânea.

Sob as referidas camadas pétreas, nas quadrículas A/4 e A/5, foi identificada uma laje de cobertura do corredor, que terá abatido na sequência da fractura de um dos esteios que a sustentava. O prolongamento desta laje para quadrícula $Z^{\prime} / 5$ obrigou à sua escavação parcial (Fig. 6, planta 5, e Fig. 8).

Junto à laje foi encontrado um pequeno esteio fincado no solo, inicialmente relacionado com a 


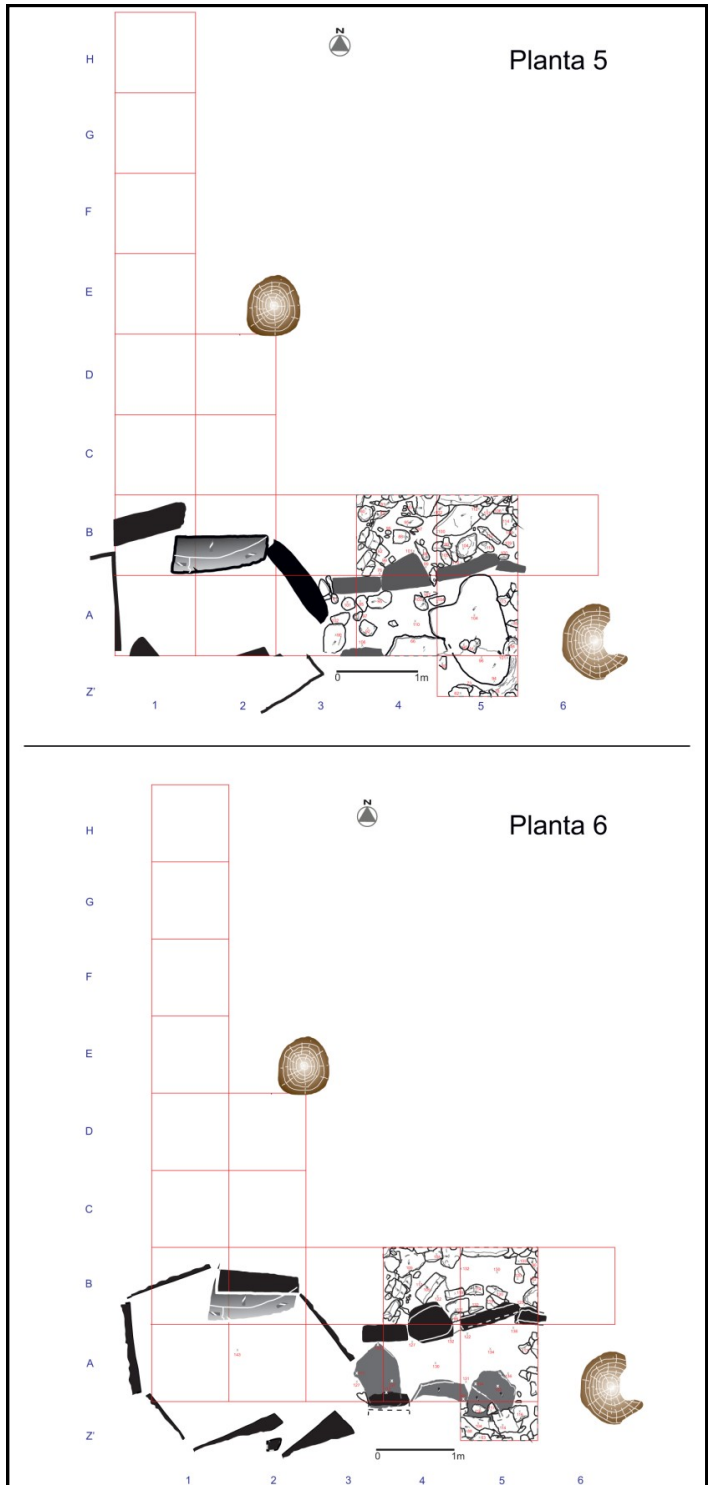

Fig. 6. Plantas da área escavada (planos 5 e 6). A partir do plano 5 a escavação centrou-se exclusivamente na câmara funerária e no interior e exterior norte do corredor. No interior da câmara, a cota $-117 \mathrm{~cm}$ marca o início do nível arqueológico preservado (que não contém qualquer estrutura pétrea). No corredor, esse nível surge a $-110 \mathrm{~cm}$. No plano 5 é visível uma laje de cobertura do corredor abatida (quadrículas Z'-A/5). O plano 6 estabelece a cota da base do depósito arqueológico no interior da câmara funerária (-143 $\mathrm{cm})$, mostra cotas relativas ao nível arqueológico preservado do corredor e mostra ainda uma "laje-soleira" $(-127 \mathrm{~cm})$ que faz a demarcação entre estes dois espaços.

Fig. 6. Plans of the excavated area (plans 5 and 6). Inside the chamber, the surface of a well preserved archaeological layer is evidenced at level $-117 \mathrm{~cm}$. This layer is evidenced in the passage at a depth of $-110 \mathrm{~cm}$. Plan 5 shows a capstone that has fallen into the passage area (grid location Z'-A/5). Plan 6 shows the bottom of the archaeological layer and orthostat that delimits the area between the chamber and the passage.

sustentação da cobertura do corredor. Após a sua exumação concluiu-se que tal função não seria viável em função das suas reduzidas dimensões. Deste modo, avançou-se a hipótese de se tratar de um elemento de "carácter simbólico", que por

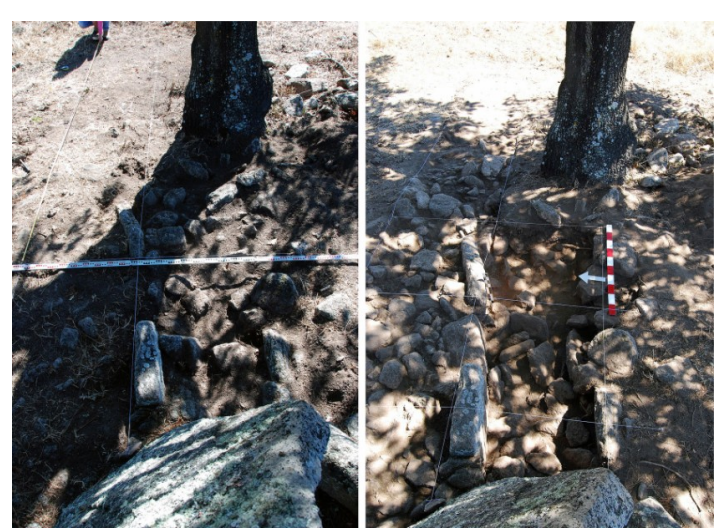

Fig. 7. Corredor intratumular antes da escavação e no seu início (foto da esquerda e da direita, respectivamente)

Fig. 7. Passage before and during excavation (left and right photo, respectively)

qualquer razão marcaria aquele sector do corredor de acesso à câmara funerária. Curiosamente, o aspecto "esteliforme" deste pequeno esteio poderá ir ao encontro desta interpretação (Fig. 8).

A uma cota inferior à laje de cobertura do corredor detectou-se um nível arqueológico bem preservado, do qual se exumaram diversos artefac-

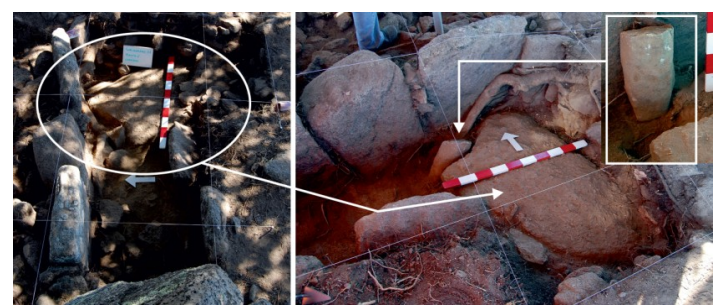

Fig. 8. Laje de cobertura do corredor abatida (quadrículas $\mathrm{A} / 4, \mathrm{~A} / 5$ e Z'/5). Observe-se também o pequeno esteio de granito fincado no solo, de aspecto "esteliforme".

Fig. 8. Collapsed capstone from the passage (grid location $\mathrm{A} / 4$, $\mathrm{A} / 5$ and Z'/5). A naturally formed "anthropomorphic" slab was found in close proximity to the capstone.

tos pré-históricos. Na quadrícula $\mathrm{A} / 5$ (que deverá coincidir sensivelmente com a zona mediana do corredor), precisamente sob a referida laje, identificou-se um conjunto de vasos cerâmicos inteiros, que poderá corresponder a um “depósito primário" (Fig. 9). Não é de excluir a hipótese desta deposição se articular com uma das últimas utilizações da anta, uma vez que, de um certo modo, ela "bloqueia" o acesso ao interior da câmara funerária.

No que diz respeito à ligação entre o corredor e a câmara, ela foi executada de forma a criar um estreitamento na zona de passagem entre estes dois espaços: os esteios do lado norte do corredor foram intencionalmente colocados segundo um eixo que não coincide com o rebordo do esteio da câmara (Fig. 2). Tal estreitamento confere à câmara uma maior "privacidade" na medida em que impede que do corredor seja possível avistar directamente o seu interior (Fig. 10).

Ao nível do solo, a demarcação da zona de passagem entre o corredor e a câmara é feita por uma espécie de "soleira" em granito, que assentava no nível alterado do substrato (Fig. 6, planta 6, e 
Fig. 11). Sob esta soleira foram identificados carvões vegetais, possivelmente relacionados com a fase de construção/ utilização inicial do monumento megalítico. Estes carvões, após análise antracológica, serão datados pelo radiocarbono.

$\mathrm{Na}$ área intervencionada do corredor atingiuse o bedrock. As quadrículas A/6 e A/7 não puderam ser escavadas dada a presença do referido carvalho.

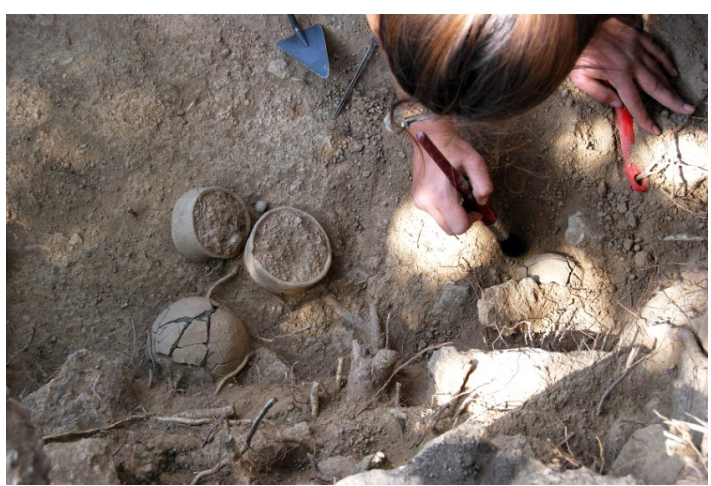

Fig. 9. Conjunto de vasos cerâmicos depositados no corredor, detectados por baixo da respectiva laje de cobertura abatida.

Fig. 9. Pottery uncovered in the passage under collapsed capstone.

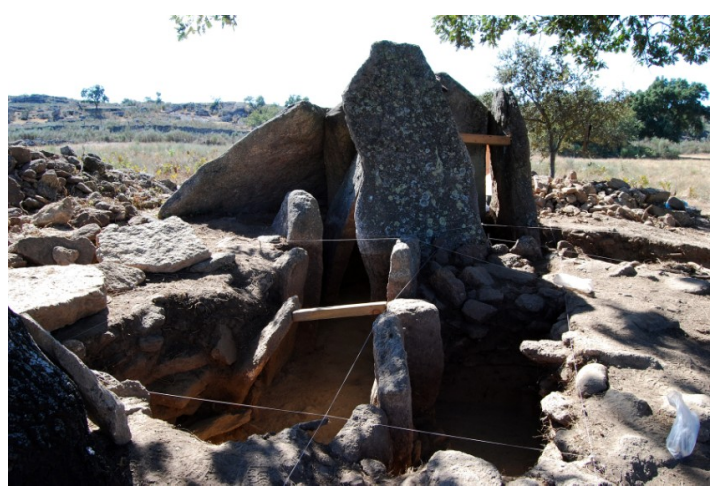

Fig. 10. Corredor e câmara funerária. Observe-se o desalinhamento intencional dos esteios do lado direito do corredor relativamente ao rebordo do esteio da câmara, com o objectivo de estreitar a passagem entre os dois espaços.

Fig. 10. In close inspection, it is possible to observe a progressive narrowing of the passage leading to the chamber.

\subsection{A Mamoa}

A abertura das quadrículas C-D-E-F-G-H/1 ainda não escavadas integralmente - permitiu estabelecer o raio aproximado da mamoa (raio actual), que será de cerca de $6 \mathrm{~m}$. Na quadrícula H/1 (Fig. 5, planta 1, e Fig. 12) constatou-se que a mamoa termina abruptamente e que não existe (ou não se conservou) qualquer estrutura de delimitação periférica. Nesta mesma quadrícula a espessura do tumulus atinge escassos centímetros.

A significativa diferença de cota entre a superfície actual da mamoa e o topo dos esteios da câmara funerária - superior a $1,70 \mathrm{~m}$ - documenta o

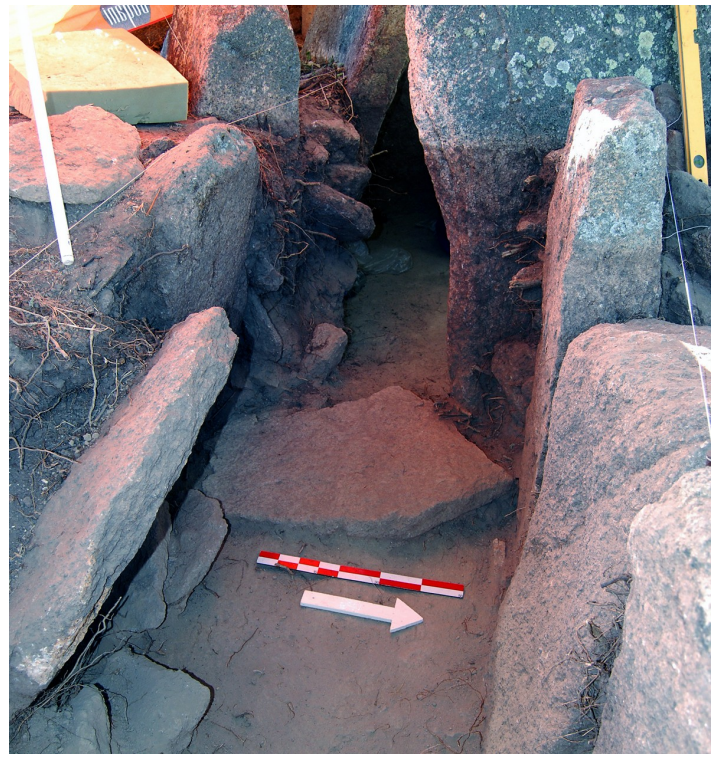

Fig. 11. "Soleira" em granito que demarca a passagem entre o corredor e a câmara funerária.

Fig. 11. Granite slab delimiting the area between the chamber and the passage.

enorme truncamento a que aquela estrutura foi sujeita. De facto, considera-se que as pedras que foram acumuladas no interior da anta (Figs. 3, 5 e 7), bem como as que fazem parte de pequenos muretes das suas imediações, terão sido arrancadas da mamoa, fundamentalmente em consequência das lavras. Posteriormente, a limpeza sucessiva das áreas agricultadas terá reconcentrado todo este material pétreo sobre o monumento megalítico, uma vez que a área por ele ocupada seria, desde logo, a menos propícia para o cultivo.

No que concerne à composição interna da mamoa (aspecto a que se procurará dar mais atenção nas próximas etapas dos trabalhos), a observação preliminar dos pequenos perfis da sanja F-GH/1 (Fig. 5, planta 1, e Fig. 12) revela uma certa alternância de "terra" areno-siltosa e blocos de granito.

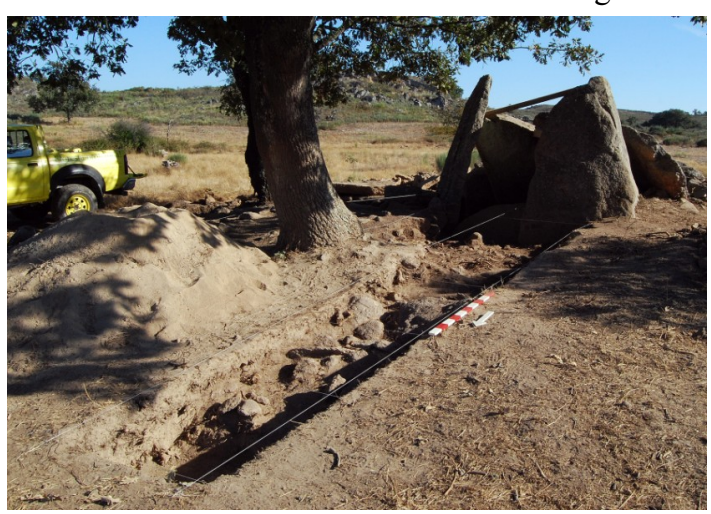

Fig. 12. Quadrículas $B, C, D, E, F, G, H / 1$. Observe-se na quadrícula em primeiro plano $(\mathrm{H} / 1)$ o limite abrupto da mamoa. Observe-se igualmente as pedras e o sedimento areno-siltoso que a compõem.

Fig. 12. The excavation of the area corresponding to grid location $\mathrm{H} / 1$ evidenced the abruptness of the mound edges. In crosssection, it was possible to identify the fabric of the mound as a mixture of silty sand and stone. 
É provável que essa alternância se mantivesse constante até à superfície original da mamoa, que se desenvolveria, muito provavelmente, até à cota da laje de cobertura do monumento.

Aparentemente, a mamoa parece encerrar pouco material arqueológico. Nas quadrículas $\mathrm{C} / 1$ 2 e D/1-2 identificaram-se alguns fragmentos cerâmicos de reduzidas dimensões, um machado de pedra polida em anfibolito e um seixo de quartzito talhado.

\section{ALGUMAS CONSIDERAÇÕES GERAIS SOBRE A CONSTRUÇÃO DO MONUMENTO MEGALÍ- TICO}

Uma primeira consideração acerca da construção do monumento megalítico relaciona-se com a escolha do local para a sua erecção. A uma escala ampla, verifica-se que a anta foi construída aproximadamente no centro de um vale pouco profundo, nas imediações de estreitas linhas de água sazonais que drenam para a Ribeira de Nisa, e sobre um solo pobre, essencialmente arenoso, de tipo litossolo (observações com base no ambiente ecológico actual). A posição que ocupa no referido vale terlhe-á conferido algum destaque na paisagem dada a morfologia aplanada do terreno em seu redor e o distanciamento relativamente aos relevos graníticos que constituem as vertentes do vale (Fig. 1c).
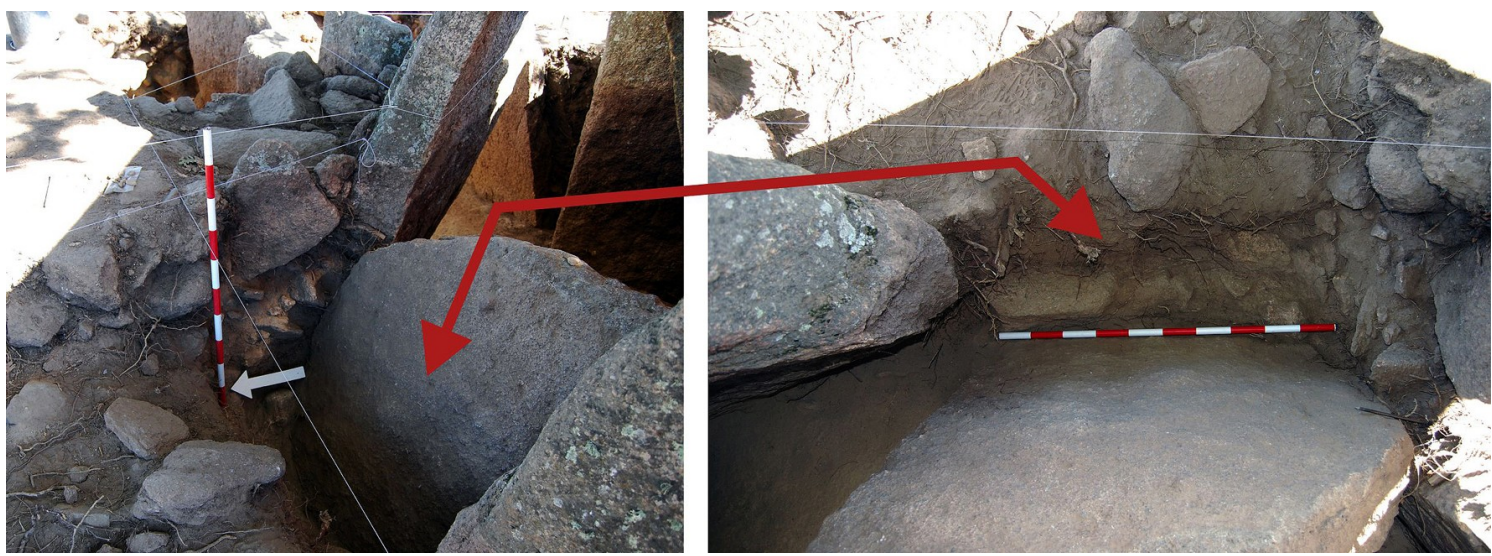

Fig. 13. Sucessão de pedras e terra visível por detrás de um dos esteios fracturados (esteio 3), que poderá corresponder à estrutura de contrafortagem da câmara megalítica.

Fig. 13. A mixture of soil and stones that was evidenced behind a fractured orthostat (orthostat 3). This deposit may be interpreted as buttressing the megalithic chamber.

à descrição da referida estrutura de forma detalhada.

No exterior norte do corredor, em contacto com o bed-rock, identificou-se uma unidade arenosiltosa amarelada, que poderá conservar, hipoteticamente, parte de um horizonte inferior de um solo contemporâneo da construção do monumento megalítico. Os esteios atravessam este depósito, assentando em alvéolos abertos no substrato (Fig. 14, corte A-A', e Fig. 15).

Sobre a referida "camada amarelada" foram colocadas pedras de dimensão decimétrica, muito
A um nível mais restrito, constata-se que a anta foi colocada sobre um filonete de uma rocha ou mineral silicioso (a determinar), visível na base da câmara funerária. Aparentemente, esta acção terá sido intencional. $\mathrm{O}$ material lítico em questão era conhecido, e por alguma razão valorizado, por parte dos construtores do monumento megalítico, tendo sido usado pontualmente em operações de talhe. Considera-se óbvia, portanto, a relação directa entre a pré-existência natural (filão) e a implantação do elemento arquitectónico naquele ponto específico, aspecto que, aliás, vai ao encontro do que tem vindo a ser defendido por inúmeros investigadores (p.e. BRADLEY 2000; CARDOSO 2010; EDMONDS \& SEABORNE 2005; INGOLD 2003; JORGE 2005; POLLARD 2006).

No que toca aos procedimentos construtivos propriamente ditos, e não obstante não ter sido possível, por questões de segurança, escavar os esteios da câmara funerária até à base, percebeu-se que os alvéolos onde eles assentam foram abertos na superfície alterada do substrato geológico.

No lado exterior da câmara, por detrás de um dos esteios fracturados, identificou-se uma sucessão de pedras e sedimento arenoso/ areno-siltoso, que parece ter funcionado como estrutura de contrafortagem da câmara megalítica (Figs. 13 e 14, corte B-B'). Uma vez que esta área (quadrículas B/1 e B/2) não foi ainda integralmente escavada, não é possível proceder 


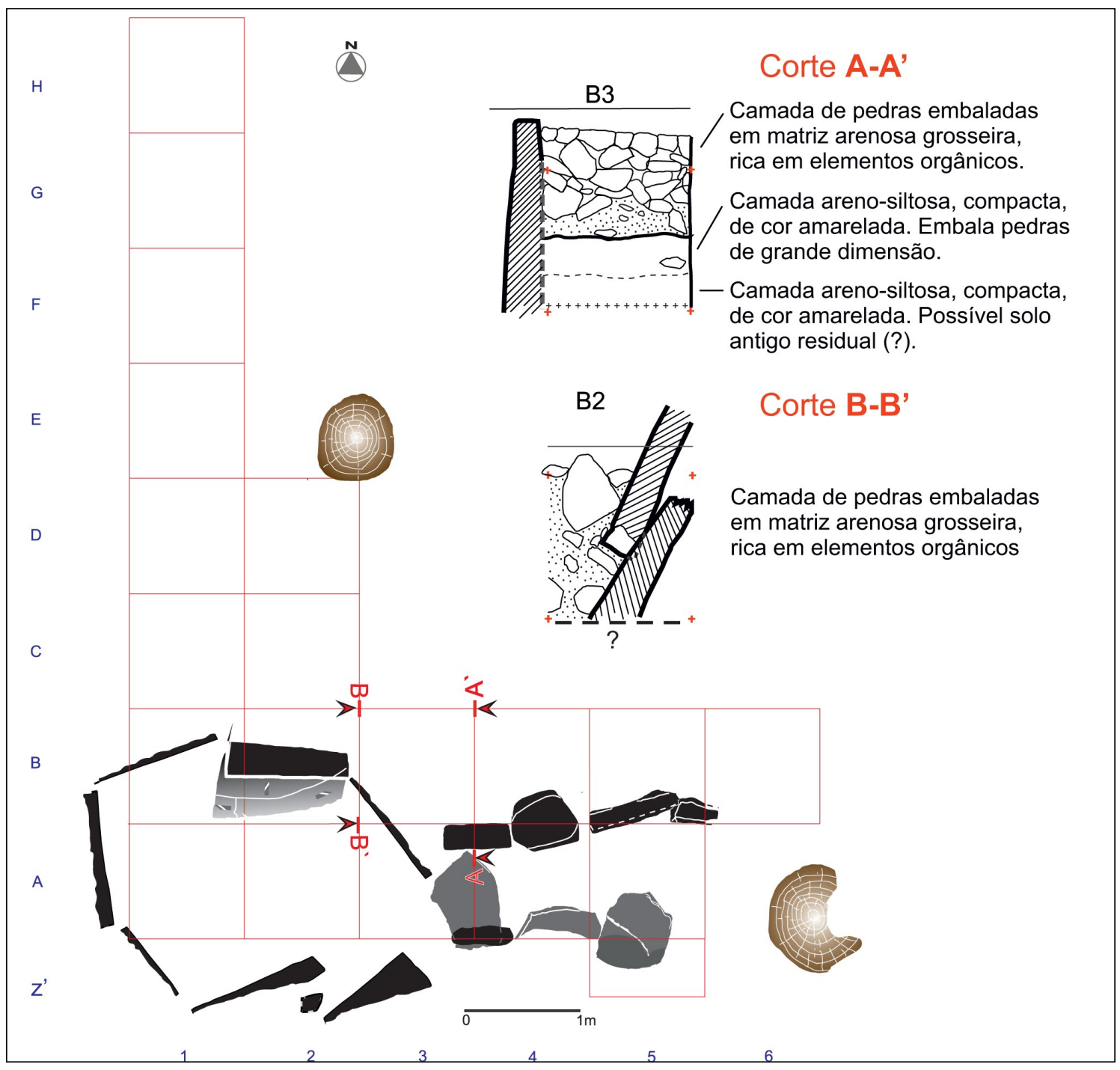

Fig. 14. Localização dos cortes A-A'e B-B'.

Fig. 14. Location of $A-A^{\prime}$ and $B-B$ ' coss-sections.

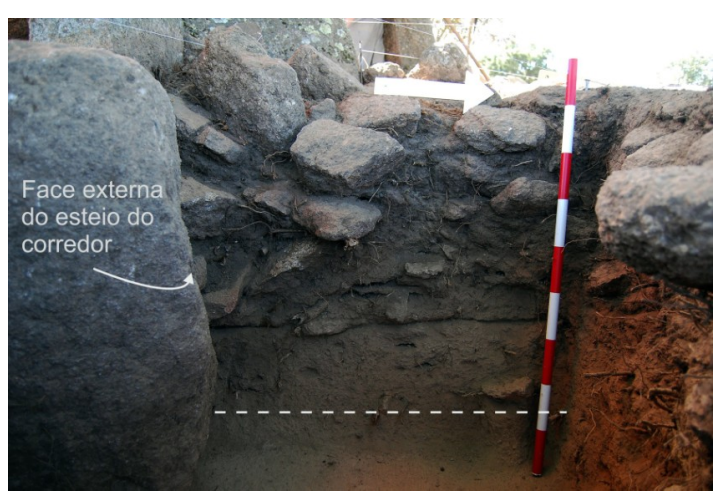

Fig.15. Depósito areno-siltoso basal que poderá corresponder ao solo contemporâneo da construção do monumento. Sobre este depósito foram colocadas diversas camadas de terra e pedra que sustentam os esteios do corredor.

Fig. 15. The silty sand layer uncovered at the bottom of the stratigraphic succession of the mound may correspond to a buried "surface" contemporary with the construction of the megalithic monument. At the top of this deposit several layers of stone and soil were deposited in order to sustain the orthostats that delimit the passage.

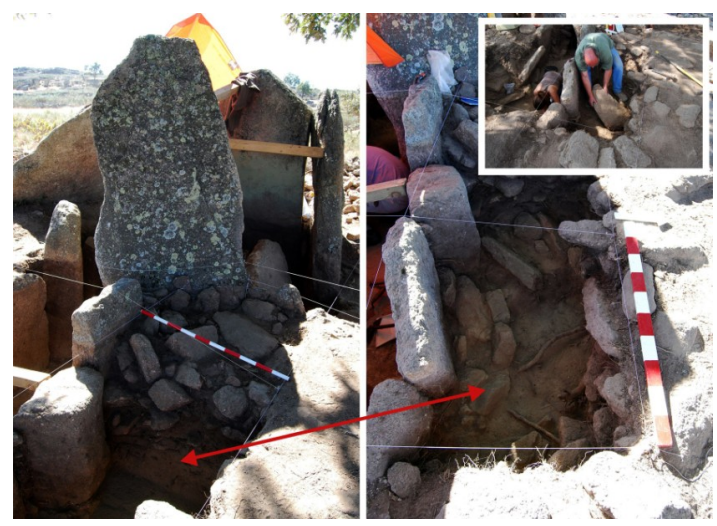

Fig. 16. A contrafortagem do corredor foi feita com pedras de dimensão decimétrica e sedimento areno-siltoso.

Fig. 16. The material used to buttress the passage is composed of silty sand sediment and decimetric stones. 


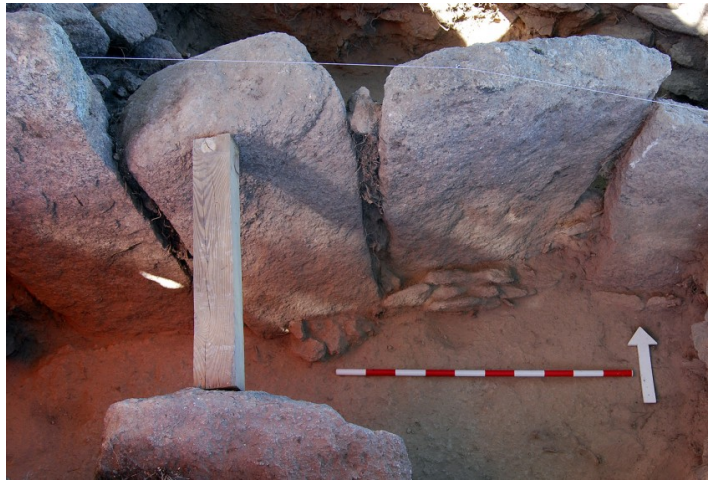

Fig. 17. Cunhas de granito colocadas na base dos esteios do corredor para a sua fixação.

Fig. 17. Granite wedges were used to sustain the passage orthostats.

\section{MATERIAL ARQUEOLÓGICO EXUMADO E CRONOLOGIA DO MONUMENTO}

Entre os materiais arqueológicos recuperados (ainda não contabilizados integralmente) destacamse alguns seixos talhados de quartzito, um número muito reduzido de produtos de talhe em rocha ou mineral filoniano (a determinar), duas pontas de seta (valor anormalmente baixo no contexto regional), um micrólito geométrico, seis machados de pedra polida em anfibolito, diversos recipientes cerâmicos inteiros (possivelmente mais de quinze tendo em conta potenciais reconstituições), duas placas de xisto completas, uma lisa e uma decorada com incisões, três contas de colar, etc. (Figs. 18 a 22).
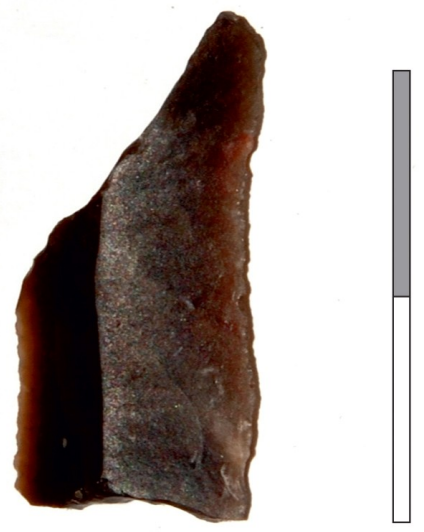

Fig. 18. Trapézio em sílex.

Fig. 18. Flint trapezoid.

Relativamente aos recipientes cerâmicos, todos eles são lisos, apresentam pequenas dimensões e possuem formas típicas dos contextos megalíticos alentejanos (formas globulosas, cilíndricas, carenadas e com colo curto).

A placa decorada parece corresponder a um reaproveitamento de uma outra placa mais antiga: o padrão decorativo mostra uma certa obliquidade relativamente ao plano vertical do suporte e terá sido truncado lateralmente na sequência do recorte da nova placa, não sendo de excluir, também, a hipótese de regravações (BUENO RAMÍREZ 2010). Por outro lado, este reaproveitamento deverá justificar o contorno tão particular que a peça apresenta. A placa lisa, por seu turno, evidencia uma ténue coloração avermelhada, que pode indiciar a presença de pigmento (hipótese a confirmar) (BUENO RAMÍREZ et al. 2008b).

Os machados de pedra polida têm dimensões entre os 18 e os $11 \mathrm{~cm}$, pelo menos num caso observam-se levantamentos distais decorrentes de utilização e, de um modo geral, associam-se aos diversos espaços do monumento, nomeadamente ao corredor (BUENO RAMÍREZ et al. 2012) e a frestas entre esteios da câmara.

Este conjunto artefactual - em particular alguns recipientes cerâmicos -, conjugado com a

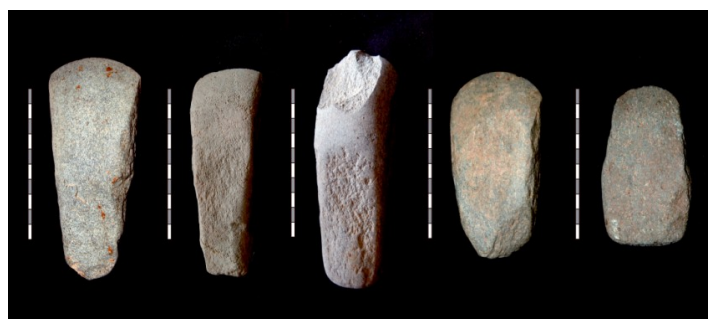

Fig. 19. Machados de pedra polida (anfibolito). Fig. 19. Polished stone axes (amphibolite).

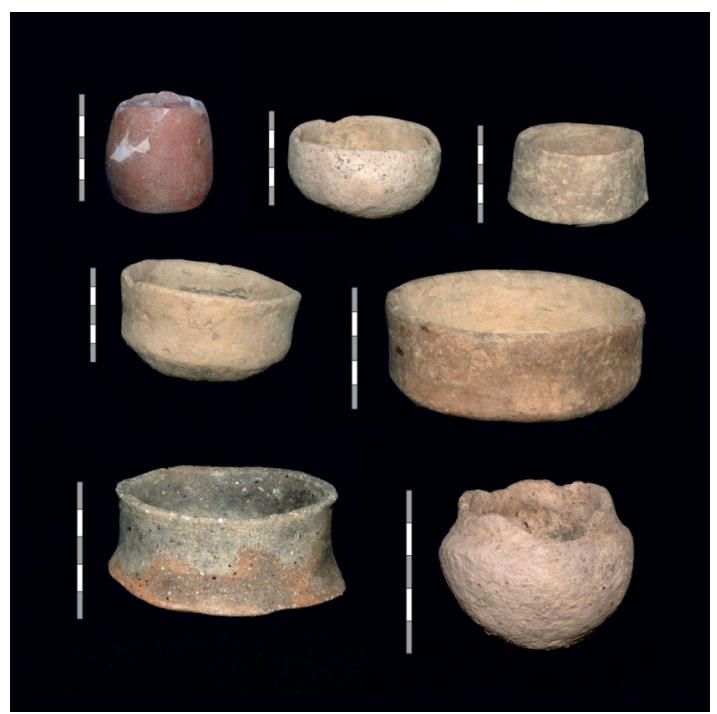

Fig. 20. Vasos cerâmicos do corredor e da câmara funerária. Fig. 20. Pottery from the passage and chamber.

arquitectura do monumento, poderá, provisoriamente, remeter a Anta dos Currais do Galhordas para os finais do Neolítico/ inícios do Calcolítico (LEISNER \& LEISNER 1951) - ou seja, para a transição do IV para o III milénio cal BC (ANDRADE 2009; BUENO RAMÍREZ et al. 2006; OlIVEIRA 1997, 2006, 2010; PARREIRA 1996). Em todo o caso, pretende-se confirmar esta cronologia submetendo alguns dos carvões detectados a datação pelo radiocarbono (após o respectivo estudo antracoló- 


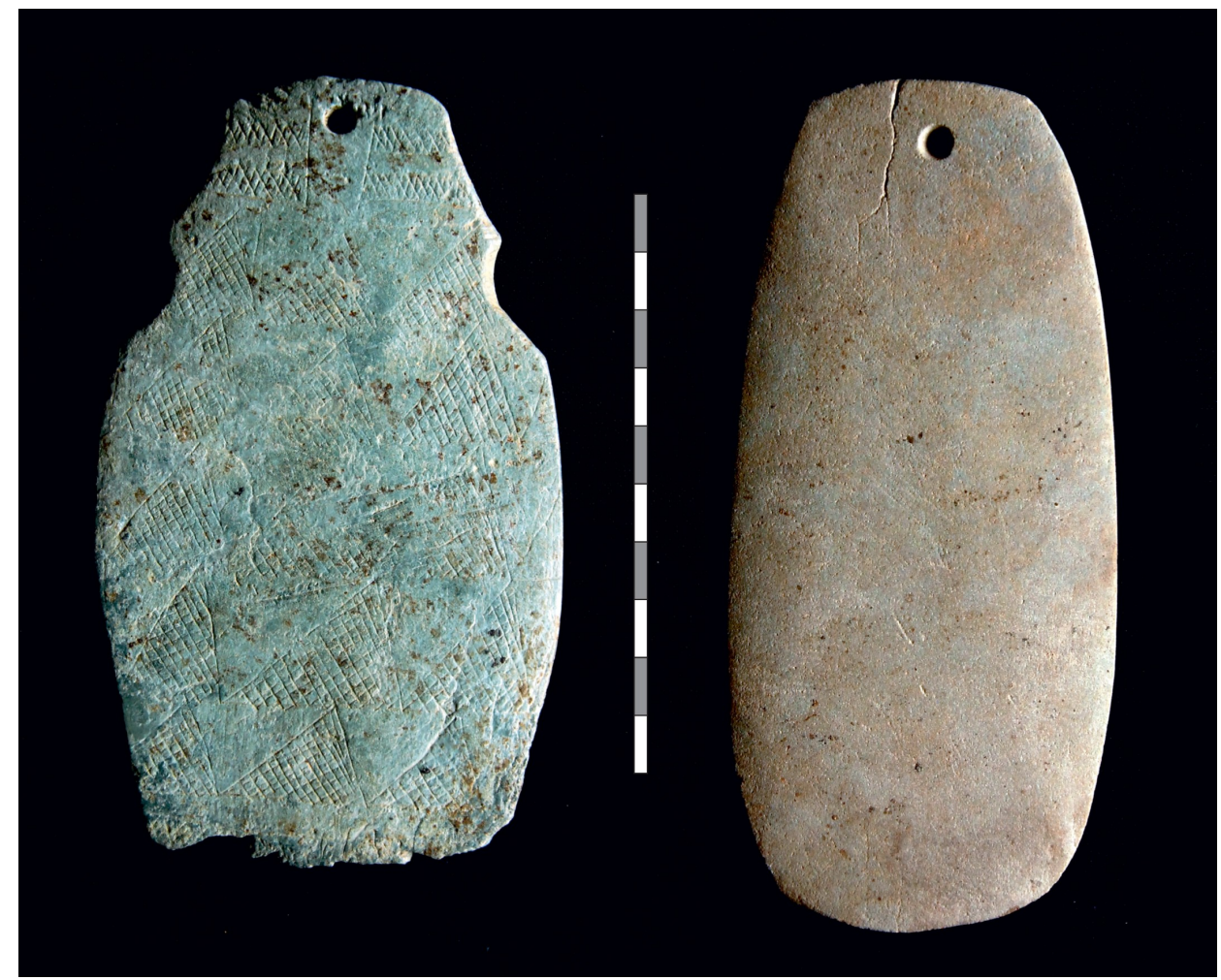

Fig. 21. Placas de "xisto" (matérias-primas a determinar).

Fig. 21. "Slate" plaques (material composition to be determined).

gico). Como foi acima referido, a localização destes carvões permitirá, eventualmente, datar o "momento" da construção/ utilização inicial da anta.

Ainda no âmbito do estudo do material exumado, procedeu-se à análise do conteúdo de um recipiente cerâmico através de cromatografia gasosa com detecção por massa, no Centro de Química da Universidade do Minho (estudo realizado por César Oliveira). Este procedimento, inovador no contexto do estudo do megalitismo português, conduziu à detecção de vestígios de diferentes substâncias orgânicas, claramente identificáveis. Brevemente serão analisados mais dois vasos, ao que se seguirá a divulgação dos resultados no seu conjunto.

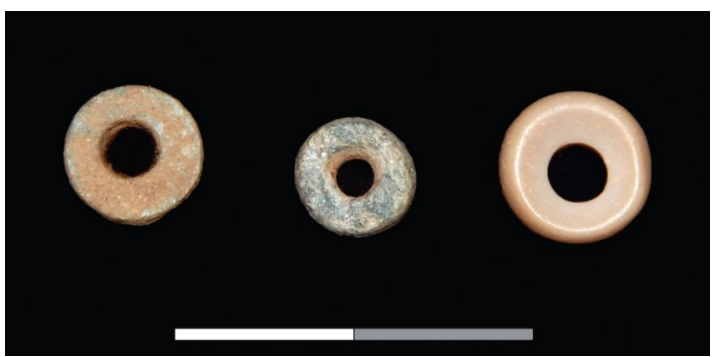

Fig. 22. "Contas de colar" (matérias-primas a determinar). Fig. 22. Stone beads (material composition to be determined).

\section{CONCLUSÕES}

Apesar da má conservação estrutural do monumento megalítico e das claras perturbações estratigráficas (sobretudo nos depósitos mais superficiais), foi possível, nesta fase inicial dos trabalhos, definir o espaço interior da câmara funerária, parte do corredor e a área de ligação entre estas duas estruturas. Deste modo, pode confirmarse que a Anta dos Currais do Galhordas corresponde a um monumento megalítico de câmara poligonal e corredor longo, encontrando-se este último ligeiramente desviado relativamente ao eixo de simetria da anta. Em todo caso, o corredor cumpre a normal orientação a este, tal como acontece na maior parte dos monumentos megalíticos da região (OliveIRA 1997).

Em relação à mamoa (apenas parcialmente escavada), ela parece ser composta essencialmente por blocos de granito embalados num sedimento arenoso, por vezes areno-siltoso, adquirindo, por isso, uma grande compactidade. Aceita-se a hipótese desta combinação de pedras e "terra" ter sido usada desde o nível do solo primitivo ao limite superior da mamoa, que deveria coincidir com a laje de cobertura da câmara megalítica.

Quanto ao material arqueológico exumado, e

${ }^{2} \mathrm{O}$ autor agradece às Profs. Doutoras Mariana Diniz (Universidade de Lisboa) e Primitiva Bueno (Universidade de Alcalá de Henares, Espanha) os comentários relativos aos materiais arqueológicos, nomeadamente às placas de "xisto". 
tendo como referência outras antas do concelho de Castelo de Vide, pode dizer-se que ele não é abundante, sobretudo no que toca à pedra talhada (o micrólito geométrico e as pontas de seta perfazem um total que não deve ultrapassar os três artefactos). Os vasos cerâmicos, por sua vez, aparecem em número bem mais significativo e demonstram alguma variedade morfológica. Como se referiu, algumas das formas poderão remeter a construção/ utilização do monumento para a transição do IV para o III milénio cal BC.

Ainda no âmbito do estudo dos materiais arqueológicos, prevê-se que a realização de mais análises ao conteúdo dos vasos cerâmicos poderá trazer novos e importantes dados, não só sobre as práticas funerárias neolíticas, mas também sobre outros aspectos de natureza paleoeconómica.

Por último, refira-se que existe alguma expectativa no que toca à possibilidade de datar a Anta dos Currais do Galhordas pelo 14C em função da ocorrência de material antracológico sob uma estrutura que se crê associada ao "momento" da sua construção e/ou utilização inicial.

\section{AGRADECIMENTOS}

O autor agradece: A António Pita, Presidente da Câmara Municipal de Castelo de Vide, o convite para coordenar os trabalhos de escavação arqueológica na Anta dos Currais do Galhordas, bem como o apoio institucional e pessoal prestado durante e após a sua realização; À Câmara Municipal de Castelo de Vide o financiamento e toda a logística, fundamentais para a concretização deste estudo; A colaboração dos Mestres Daniela Ferreira e Filipe Vaz, dos técnicos da Secção de Arqueologia daquela mesma Autarquia João Magusto (autor dos desenhos de campo e de gabinete) e Nuno Félix, e de Conceição Filomeno e João Rosado. Aos revisores do texto agradece as diversas sugestões que contribuíram para o seu melhoramento.

\section{BIBLIOGRAFIA}

ANDRADE, M.A.S. 2009. Megalitismo e comunidades megalíticas na área da Ribeira Grande (Alto Alentejo). Definição e caracterização do fenómeno de «megalitização» da paisagem na área austral do Norte Alentejano. Dissertação de Mestrado, Faculdade de Letras da Universidade de Lisboa.

BRADLEY, R. 2000. An Archaeology of Natural Places. London: Routledge.

BUENO RAMÍREZ, P. 2010. Ancestros e imágenes antropomorfas muebles en el âmbito del megalitismo occidental: las placas decoradas. In C. Cacho, R. Maicas, G. Eduardo, J.A. Martos (eds.) Los ojos que nunca se cierran. Ídolos en las primeras sociedades campesinas. Publicação em suporte DVD do Museo Arqueológico Nacional, Ministério de Cultura, Madrid: 39-77.

BUENO RAMÍREZ, P.; BARROSO, R.; BALBÍN, R. \& CARRERA, F. 2006. Megalitos y marcadores gráficos en el Tajo Internacional: Santiago de Alcántara (Cáceres). Ayuntamiento de Santiago de Alcántara.
BUENO RAMÍREZ; P.; BARROSO BERMEJO, R. \& BALBÍN BEHRMANN, R. 2008a. The necropolis of Era de la Laguna, Santiago de Alcántara, Cáceres, in the context of the Megalithism of the Central Region of the International Tagus. In P. Bueno-Ramirez, R. Barroso-Bermejo \& R. BalbínBerhmann (eds.) Graphical Markers and Megalith Builders in the International Tagus, Iberian Peninsula. BAR International Series 1765: 41-59.

BUENO RAMIREZ, P.; BALBÍN BEHRMANN, R. \& BARROSO BERMEJO, R. 2008b. Models of Integration of Rock Art and Megalith Builders in the International Tagus. In P. Bueno-Ramirez, R. Barroso-Bermejo \& R. Balbín-Berhmann (eds.) Graphical Markers and Megalith Builders in the International Tagus, Iberian Peninsula. BAR International Series 1765: 5-15.

BUENO RAMÍREZ, P.; BARROSO BERMEJO, R. \& BALBÍN BEHRMANN, R. 2010. Megalitos en la cuenca interior del Tajo. Munibe (Suplemento) 32: 152-187.

BUENO RAMÍREZ, P.; BARROSO BERMEJO, R. \& BALBÍN BEHRMANN, R. 2012. Mégalithes, Statues, gravures et peintures dans le Bassin intérieur du Tage, Espagne. In M. Sohn \& J. Vaquer (Dir.) Sépultures Collectives et Mobiliers Funéraires de la Fin du Néolithique en Europe Occidentale. Toulouse: Archives d'Écologie Préhistorique: $333-358$.

CARDOSO, J.C.M. 2010. Castanheiro do Vento (Horta do Douro, Vila Nova de Foz Côa) - Um Recinto Monumental do III e II Milénio a. C.: Problemática do Sítio e das Suas Estruturas à Escala Regional. Palma, Vessants, Arqueologia i Cultura.

CRUZ, Domingos J. da 2001. O Alto Paiva: Megalitismo, Diversidade Tumular e Práticas Rituais Durante a Pré-História Recente. Dissertação de Doutoramento, Universidade de Coimbra. Policopiado. Disponível on-line: http://www.academia.edu/731217/ O_Alto_Paiva_megalitismo_diversidade_tumular_e praticas_rituais_durante_a_Pre-historia_Recente

EDMONDS, M. \& SEABORNE, T. 2005. Prehistory in the Peak. Gloucestershire: Tempus.

FERNANDES, A.P.; CARVALHO, H.F.; PERES, A.M. \& PERDIGÃO, J.C. 1972. Notícia explicativa da folha 28-D (Castelo de Vide) da Carta Geológica de Portugal, na escala 1/50000. Lisboa: Serviços Geológicos de Portugal.

INGOLD, T. 2003. The perception of the environment. Essays in livelihood, dwelling and skill. London: Routledge.

JORGE, S.O. 2005. O Passado é Redondo. Dialogando com os Sentidos dos Primeiros Recintos Monumentais. Porto: Edições Afrontamento.

JORGE, V.O. 1990. Arqueologia em Construção, Lisboa: Ed. Presença.

JORGE, V.O. \& BETTENCOURT, A.M.S. 1988. Sondagens arqueológicas na mamoa 1 de Chã de Parada (Baião, 1987). Arqueologia 17: 73-118. 
LEISNER, G. \& LEISNER, V. 1951. Antas do Concelho de Reguengos de Monsaraz. Lisboa: Instituto para a Alta Cultura (reedição Uniarq/INIC, 1985).

OLIVEIRA, J. 1997. Monumentos Megalíticos da Bacia Hidrográfica do Rio Sever. Edição especial de Ibn Maruan - Revista Cultural do Concelho de Marvão, Lisboa.

OLIVEIRA, J. 2000. Economia e sociedade dos construtores de megálitos da bacia do Sever. Actas do $3^{\circ}$ Congresso de Arqueologia Peninsular, vol. III, Porto: ADECAP: 429-444.

OLIVEIRA, J. 2006. Património arqueológico da Coudelaria de Alter e as primeiras comunidades agropastoris. Lisboa: Edições Colibri e Universidade de Évora.

OLIVEIRA, J. 2010. Neolítico e Megalitismo na Coudelaria de Alter. In V.S. Gonçalves \& A.C. Sousa (eds.) Transformação e Mudança no Centro e Sul de Portugal: o $4^{\circ}$ e o $3^{\circ}$ milénios a.n.e. Actas do Colóquio Internacional (Cascais, 2005). Câmara Municipal de Cascais: 357-397.
OLIVEIRA, J.; PEREIRA, S. \& PARREIRA, J. 2010. Nova Carta Arqueológica do Concelho de Marvão. Edições Colibri e Câmara Municipal de Marvão.

PARREIRA, R. 1996. O conjunto megalítico do Crato (Alto Alentejo): contribuição para o registo das antas portuguesas. Dissertação de Mestrado em PréHistória e Arqueologia apresentada à Faculdade de Letras da Universidade do Porto.

POLLARD, J. 2006. Solid Nature and Ephemeral Architecture? Understanding the Architecture of Earlier Neolithic Occupation in Southern Britain from a Dwelling Perspective. In V.O. Jorge et al. (eds.) Approaching "Prehistoric and Protohistoric Architectures" of Europe from a "Dwelling Perspective". Proceedings of the TAG Session - Sheffield 2005 (Journal of Iberian Archaeology 8), Porto: ADECAP: 41-51.

Processo Anta dos Currais do Galhordas, Secção de Arqueologia da Câmara Municipal de Castelo de Vide, inventário $\mathrm{n}^{\circ} 164$ (Documento interno da Secção de Arqueologia da CMCV). 